\title{
Erratum to: Intraforaminal ozone therapy
}

\author{
Manuel Cunha e $\mathrm{Sa}^{1} \cdot$ Vítor M. Gonçalves $^{1}$
}

Published online: 19 January 2016

(C) Springer-Verlag Wien 2016

\section{Erratum to: Acta Neurochir}

DOI 10.1007/s00701-015-2658-3

The co-author was inadvertently omitted in the original article and is now corrected in the authorgroup of this article.

$\triangle$ Manuel Cunha e Sa

mcunhaesa@gmail.com

Vítor M. Gonçalves

vg81@sapo.pt

1 Servico de neurocirurgia, Hospital Garcia de Orta, Av. Torrado da Silva, 2801-951 Almada, Portugal 